\title{
Chikungunya and Its Interaction With the Host Cell
}

\author{
Licia Bordi • Claudia Caglioti • Eleonora Lalle • \\ Concetta Castilletti • Maria Rosaria Capobianchi
}

Published online: 21 January 2015

(C) Springer International Publishing AG 2015

\begin{abstract}
Chikungunya virus (CHIKV) is a mosquitotransmitted alphavirus belonging to the Togaviridae family. It is a virus with a single-stranded, positive sense RNA genome, maintained in a sylvatic and urban cycle, involving humans and mosquitoes from Aedes species, mainly Aedes aegypti and Aedes albopictus. In less than 10 years, CHIKV has spread from the coast of Kenya throughout the Indian Ocean, Pacific Ocean, and Caribbean regions, causing millions of infections in over 50 countries. In other words, CHIKV has emerged as a true global pathogen. The clinical signs include nonspecific flu-like symptoms and a characteristic rash accompanied by joint pain that may last long time after the resolution of the infection. The molecular mechanism underlying the chronic polyarthralgia in patients is not well understood. In this review, we summarize the CHIKV genome organization, replication, epidemiology, clinical manifestations, and immunopathogenesis with particular emphasis on host-pathogen interactions.
\end{abstract}

This article is part of the Topical Collection on Viral Tropical Medicine

L. Bordi $(\bowtie) \cdot$ C. Caglioti $\cdot$ E. Lalle $\cdot$ C. Castilletti

M. R. Capobianchi

Laboratory of Virology, Padiglione Baglivi, National Institute for

Infectious Diseases "L. Spallanzani”, Via Portuense 292,

00149 Rome, Italy

e-mail: licia.bordi@inmi.it

C. Caglioti

e-mail: claudia.caglioti@inmi.it

E. Lalle

e-mail: eleonora.lalle@inmi.it

C. Castilletti

e-mail: concetta.castilletti@inmi.it

M. R. Capobianchi

e-mail: maria.capobianchi@inmi.it
Keywords CHIKV · Immunopathogenesis · Host cell · Arthralgia · Replication · Dissemination · Vectors . Clinical manifestations · Genome organization

\section{Introduction}

Chikungunya virus (CHIKV), an arbovirus transmitted by mosquito vectors, is an alphavirus belonging to the Togaviridae family. The virus belongs to the Semliki forest complex, and is closely related to O'nyong'nyong virus found in Africa, to Ross-River virus in Australia, and with a lesser extent to Mayaro virus circulating in America [1]. The latter is circulating in forests in the Caribbean (e.g., Trinidad) and South America in sylvatic mosquito vectors [2]. Chikungunya fever (CHIKF) derives its name from Makonde, a language spoken in south Tanzania, and means "that which bends up", referring to the posture of patients afflicted with severe joint pain characterizing this infection [3].

CHIKV has long remained exotic to the western hemisphere. Major epidemics appear and disappear cyclically, usually with an inter-epidemic period ranging from 7 to 20 years [4-6]. The emergence of the Indian Ocean lineage changed the view on CHIKV when it caused an unprecedented disease burden in India and in the islands of the Indian Ocean between 2005 and 2008 [7, 8]. Since the beginning of the outbreak in the Indian Ocean region, more than 1,000 imported CHIKV cases have been detected among European and American travelers returning from the affected areas [1,9], giving rise, in 2007, to the first autochthonous (human-to-mosquito-to-human transmission) European outbreak in Italy and a smaller outbreak in France [3, 10-12]. From 2009 to 2013, autochthonous transmission of CHIKV was also observed for the first time in many other countries, including New Caledonia, Papua New Guinea, Bhutan, and Yemen [13•, 14-17]. The rapid and explosive spread of CHIKV prompted the Pan 
American Health Organization (PAHO) and the Centers for Disease Control and Prevention (CDC) to release a preparedness guide that predicted potential future CHIKV epidemics in the Americas [17]. In fact, on 6 December 2013, the World Health Organization (WHO) reported the first local transmission of CHIKV in the western hemisphere on the Caribbean island of Saint Martin with two laboratory-confirmed cases of Chikungunya without a travel history. By July 2014, CHIKV had caused more than 750,000 cases of disease in more than 20 countries in the Caribbean and Central (Costa Rica and El Salvador) and South America $[17,18]$ raising concern about virus spread in continental America highly infested with A. aegypti and A. albopictus mosquitoes [2]. CDC has lately reported many imported cases of CHIKV infection in the continental USA as well as locally acquired cases in Florida, Georgia, Minnesota, Mississippi, Oklahoma (Tulsa County), Rhode Islands, and Tennessee (Knoxville) [17, 19]. At last, on 21 October 2014, WHO was notified by the National IHR Focal Point for France of 4 cases of Chikungunya locally acquired infection in Montpellier, France [20]. Thus, in less than 10 years, CHIKV has spread from the coast of Kenya throughout the Indian Ocean, Pacific, and Caribbean regions, causing millions of cases of disease in over 50 countries. In other words, CHIKV has emerged as a true global pathogen [17].

\section{Vector and Reservoir}

Two distinct transmission cycles have been well documented for CHIKV: an enzootic sylvatic cycle and an endemic/ epidemic urban cycle. The African sylvatic cycle likely involves several arboreal Aedes mosquitoes species as vectors (Aedes furcifer, Aedes vittatus, Aedes fulgens, Aedes luteocephalus, Aedes dalzieli, Aedes vigilax, Aedes camptorhynchus) and nonhuman primates as reservoir/ amplifying hosts. In Africa, the enzootic transmission cycle can spill over to infect people who live nearby, and enzootic mosquito vectors may be involved in inter-human transmission during small outbreaks [21, 22]. Endemic/epidemic transmission cycles were established when the virus was introduced into Asia around 1950 and into the Indian Ocean region, India, and then Southeast Asia since 2005 [23]. Therefore, urban transmission cycle relies only on $A$. aegypti and/or A. albopictus anthropophilic vectors that can initiate human-mosquito-human transmission and human amplification hosts. This endemic/epidemic cycle results in high levels of human exposure to mosquito transmission, particularly because these vectors live in close proximity to people. The behavior and ecology of $A$. aegypti, in particular, are ideal for epidemic transmission because adult females prefer to feed on humans, often take several blood meals during a single gonotrophic cycle, oviposit in artificial containers as their preferred larval sites, and rest inside houses with ready access to human hosts $[3,24]$. A. albopictus is zoophilic and anthropophilic, is aggressive, silent, active all-day long, and has a lifespan longer than other mosquitoes (up to 8 weeks). In the last decades, it has expanded to several areas previously known to be Aedes-free [25].

Mosquito vector competence to CHIKV seems to be determined by genotype-by genotype interactions, in which successful transmission depends on some specific combination of mosquito and viral genetic characteristics [26-29]. CHIKV has 4 major lineages: West Africa, Asian, East-CentralSouth Africa (ECSA) and the Indian Ocean, a monophyletic lineage descendant from the ECSA group [13•]. The CHIKV lineages have displayed distinct transmission efficiencies in mosquito vector species and populations $[26,30]$. Throughout the 2005-2006 CHIKV epidemic in the Indian Ocean region, a CHIKV lineage strain harboring a substitution of an alanine to valine at position 226 of the E1 envelope glycoprotein (E1-A226V) appeared [27, 28, 31]. This mutation has been clearly demonstrated to increase viral fitness in the $A$. albopictus vector $[27,28]$. Surprisingly, despite its dramatic effect on transmissibility, this mutation has not been detected in previous CHIKV strains of the ECSA genotype or in endemic Asian lineages. Although A. albopictus is native to Southeast Asia, there is no evidence that this species has played a major role in transmission of endemic Asian CHIKV strains. Conversely, A. aegypti had been consistently incriminated as the epidemic vector before the introduction of the Indian Ocean strains [30].

It was later shown that other positions in the E2 glycoprotein, i.e.,W64R and E208K, exert epistatic effects on the position E1-226V [31, 32], and some substitutions can block the adaptation of E1-A226V to A. albopictus [33]. These epistatic interactions are lineage specific. Moreover, recent study demonstrated that CHIKV strain involved in the Caribbean outbreak belongs to the Asian genotype. The Asian genotype was better transmitted by $A$. aegypti (although it was efficiently transmitted A. albopictus) due to the presence of a treonine in the E1-98 region which blocks the ability of Asian genotype virus to adapt to $A$. albopictus via E1-A226V mutation [26, 30, 34]. Determination of vector competence of mosquito populations is a key parameter in evaluating the risk of CHIKV transmission and spread [26].

Human beings serve as the main CHIKV reservoir during epidemic periods. In Africa, some animals (monkeys, rodents, and birds) constitute the virus reservoir during not-epidemic periods, sustaining virus circulation in the environment in the absence of human cases. Outbreaks might occur in monkeys when herd immunity is low; the animals develop viremia but no pronounced physical manifestations [3, 35, 36]. An animal reservoir has not been identified in Asia, where humans appear to be the only host [3]. 


\section{Clinical Manifestations}

After infection with CHIKV, there is a silent incubation period ranging 1 to 12 days [4, 37]. Clinical onset is abrupt, with high fever, headache, back pain, myalgia, and arthralgia. Poly-arthralgia is reported in $87-98 \%$ of cases and can be intense, affecting mainly the extremities (ankles, wrists, phalanges) but also the large joints [37-41]. Cutaneous manifestations were reported in about $40-50 \%$ of cases, and consist of a pruriginous maculopapular rash predominating on the thorax. The clinical presentation may involve also facial edema and, in children, a bullous rash with pronounced sloughing, localized petechiae and gingivorrhagia [42, 43]. Radiological findings are normal, and biological markers of inflammation (erythrocyte sedimentation rate and Creactive protein) are normal or moderately elevated [42, 44]. Iridocyclitis and retinitis are the most common ocular manifestations associated with CHIKF; less frequent ocular lesions include episcleritis. All ocular manifestations have a benign course with complete resolution and preservation of vision. Retinitis shows gradual resolution over a period of 6 to 8 weeks [45]. Erratic, relapsing, and incapacitating arthralgia is the hallmark of Chikungunya, although it rarely affects children. These manifestations are normally migratory and involve small joints of hands, wrists, ankles, and feet with pain on movement. The symptoms generally resolve within 710 days, except for joint stiffness and pain: up to $12 \%$ of patients still have chronic arthralgia 3 years after onset of the illness. Arthralgia experienced by CHIKV patients closely resembles the symptoms induced by other viruses like RRV and BFV [46, 47]. Neurological complications such as meningoencephalitis were reported in a few patients during the first Indian outbreak in 1973, and during the 2006 Indian outbreak [48-50]. Moreover, during the 2006 Indian-Ocean outbreak, rare cases of GuillainBarré syndrome (GBS) associated with CHIKV infection have been described [51, 52]. The possible mechanisms underlying these processes remain unknown, even if it was found that mouse central nervous system (CNS) tissues such as the choroid plexi could also be targets of CHIKV, lending more credence to the fact that CHIKV infections do affect CNS cells and tissues [53]. Other rare complications described after CHIKV infection are mild hemorrhage, myocarditis, and hepatitis [54].

CHIKV is not generally considered to be a life-threatening disease. Usually, the clinical course is fairly mild, but fatal cases directly or indirectly linked to infection with CHIKV have been observed during the Indian-Ocean outbreak [55]. The main evidence of a mortality linked to CHIKF epidemics has been obtained in La Réunion, Mauritius, and India, by comparing expected and observed mortality data. In all cases, during the months when the epidemics were raging, the observed mortality significantly exceeded the expected one. In particular, in La Réunion, the monthly crude death rates in February and March 2006 were 34.4 and $25.2 \%$ higher, respectively, than expected. This corresponded to 260 excess deaths (an increase of $18.4 \%$ ) with a rough estimate of the case-fatality rate for CHIKF of $\approx 1 / 1000$ cases. The casefatality rate calculated on increased crude death rates in Mauritius and Ahmedabad, India, is substantially higher than that calculated in La Réunion: approximately $4.5 \%(15,760$ confirmed or suspected cases and 743 excess deaths) and $4.9 \%(60,777$ confirmed or suspected cases and 2,944 excess deaths), respectively $[56,57]$. These differences may be attributed to many factors (greater disease severity, preexisting patient conditions, different patient management, or coincident excess deaths from other causes) but may also be due to a different efficacy of the surveillance systems for CHIKF that probably worked poorly in Mauritius and India, leading to underestimating the total number of cases [58]. The possible link between CHIKV infection and multiorgan failure is still under investigation [3].

\section{Genomic Organization and Viral Replication}

CHIKV is a small spherical enveloped virus of about 60 $70 \mathrm{~nm}$ in diameter that consists of a capsid core, two glycoproteins (E1 and E2) and a lipid bilayer in addition to a singlestranded positive sense RNA genome of approximately $11.8 \mathrm{~kb}$ encoding 4 nonstructural (nsP1-4) and 5 structural proteins $(\mathrm{C}, \mathrm{E} 3, \mathrm{E} 2,6 \mathrm{~K}$, and $\mathrm{E} 1)$ that are driven by two open reading frames (ORFs) $[59,60]$. The $\mathrm{E} 1$ glycoprotein is a class II fusion protein that mediates fusion of the viral and host cell membranes during virus entry, while the E2 glycoprotein is a 50-kDa type I trans-membrane glycoprotein that is responsible for receptor binding to host cells [61, 62].

Viral replication is initiated by attachment of viral envelope to host cell receptors [63], followed by low pH-mediated membrane fusion and delivery of the viral nucleocapsid into the cytoplasm (Fig. 1) [64, 65]. A detailed entry mechanism description is not available so far. Some authors implicate a clathrin-dependent pathway [64, 66], whereas other authors have proposed that CHIKV enters by a clathrin-independent, but Eps15-dependent pathway [65]. These later authors also have found evidence that multiple pathways maybe employed by CHIKV to enter into cells, as already proposed with dengue virus (DENV) [67, 68]. Another possible explanation could be that there are cell type specific differences implied in the entry mechanism [62].

So far, host cellular receptors of CHIKV have not been well documented. However, some authors have identified prohibitin (PHB) as CHIKV-binding protein expressed by microglial cells [62], while other authors suggest that the heat 
Fig. 1 Life cycle of CHIKV in infected cells and dissemination to different tissues and organs. Schematic representation of CHIKV entry in infected cells, replication, genome packaging, release, and dissemination to tissues and organs. Figure modified from Caglioti et al, 2013 [3]

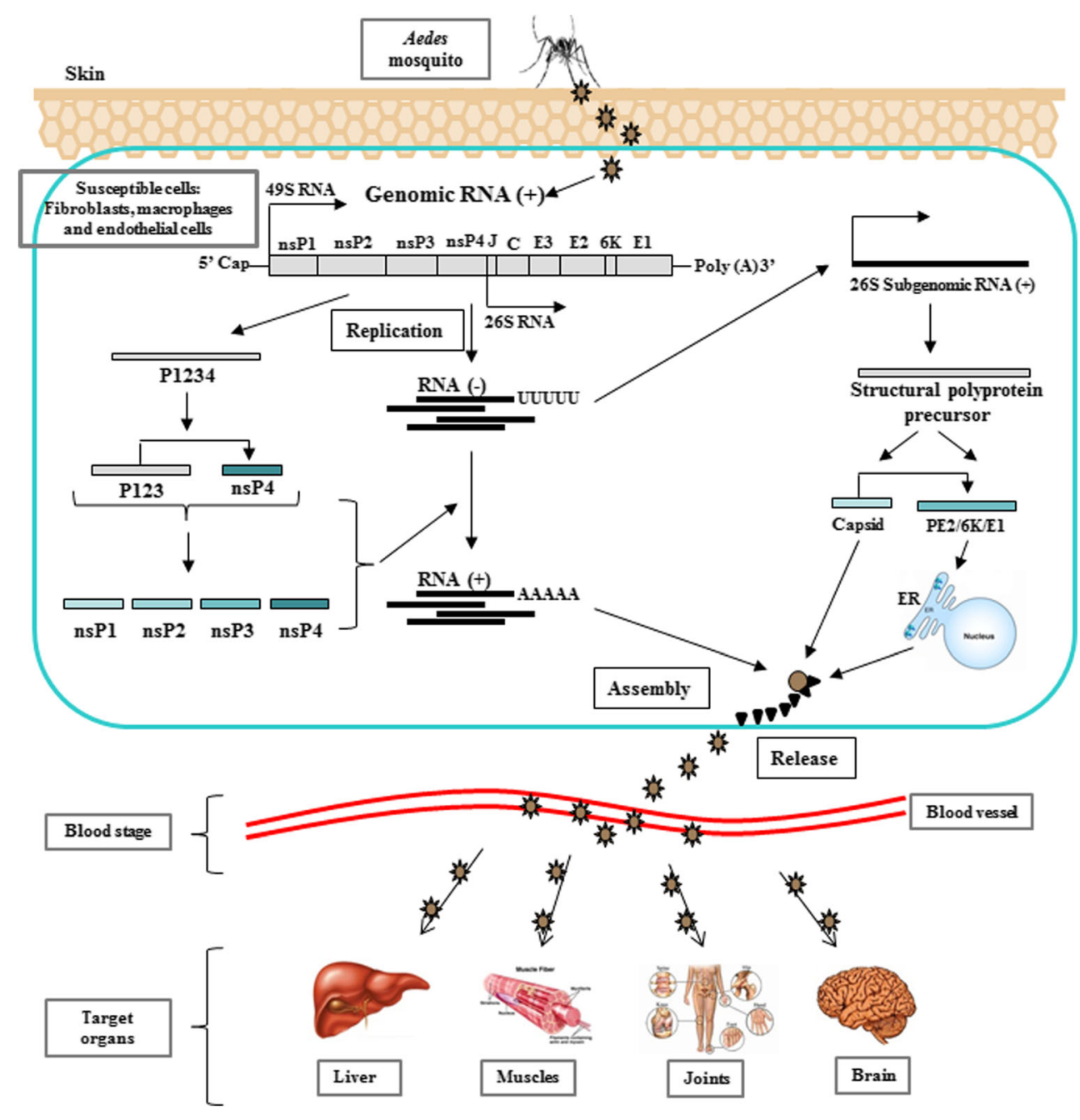

shock proteins (HSPs) may play a crucial role in the virus entry. More in detail, Paingankar and colleagues (2014) have identified HSP70 as virus-binding protein in HEK-293T cells and Vero-E6, also assessing that STAT-2 could be involved in this mechanism, especially in Vero-E6 cells. Furthermore, they demonstrated a direct interaction between actin and CHIKV, thus supporting the hypothesis that actin and actinassociated proteins might play a crucial role in the entry and transport of CHIKV [69•]. Moreover, in a very recent study, the polarized entry of CHIKV toward the apical domain of polarized cells has been demonstrated, suggesting that the CHIKV receptors could be pre-dominantly sorted to the apical domain, allowing CHIKV to attach to the receptors and enter the polarized cells preferentially at the apical plasma membrane [70•].

Following virus entry, positive-sense genomic RNA acts directly as mRNA and is partially translated ( $5^{\prime}$ end) to produce non-structural proteins (nsPs). These proteins are responsible for replication and formation of a complementary negative strand, the template for further positive-strand synthesis.
Subgenomic mRNA (26S) replication occurs through the synthesis of full-length negative intermediate RNA, which is regulated by nsP 4 and $\mathrm{p} 123$ precursor in early infection, and later by mature nsPs [71, 72]. To this regard, it has been recently demonstrated that Hsp90 positively regulates CHIKV replication by stabilizing nsP2 levels during infection [73]. The $26 \mathrm{~S}$ sub-genomic RNA encodes the polyprotein precursor for structural proteins, which is cleaved to yield $\mathrm{C}, \mathrm{pE} 2,6 \mathrm{~K}$, and E1 that are further processed and transported to the plasma membrane [74]. After the nucleocapsid protein is produced from the polypeptide, the glycoprotein $\mathrm{pE} 2$ is inserted into the endoplasmatic reticulum (ER). The $\mathrm{pE} 2-\mathrm{E} 1$ complex moves to the cell surface through the Golgi complex. Virion assembly starts in the cytoplasm with the formation of the nucleocapsid, which has viral RNA in association with 120 dimers of $\mathrm{C}$ protein $[74,75]$. Nucleocapsids are reported to move freely through the cytoplasm. The virions bud through the host cell membrane during which it acquires a lipid bilayer envelope; virus encoded E1 and E2 glycoproteins are embedded in this lipid bilayer [76]. Furthermore, a polarized release 
of CHIKV at the apical plasma membrane of polarized cells has been discovered, suggesting that CHIKV structural proteins may contain apical sorting signals that direct their sorting toward the apical domain [70].

At last, after the release, the virus disseminates quite rapidly to the blood circulatory system and then to the blood through the thoracic duct [3].

\section{Dissemination to Target Organs}

Following intradermal inoculation by infected mosquitoes, CHIKV directly enters the subcutaneous capillaries where its replication starts immediately (Fig. 1) with some viruses infecting susceptible cells in the skin, including epithelial, fibroblasts and endothelial cells, as well as monocyte derived macrophages [64]. It has been recently demonstrated that monocytes, originally thought to be non-susceptible to CHIKV infection [64], could be infected and virus growth could be sustained [77]. Local viral replication seems to be minor and limited in time, with the locally produced virus probably being transported to secondary lymphoid organs close to the site of inoculation, where infected migratory cells produce new viruses which can, in turn, infect susceptible resident cells. Even if the host is mounting a response to control the virus in the skin dermis, the virus disseminates quite rapidly to the blood circulatory system. Viruses produced in the draining lymph nodes are released into the lymph circulation and then to the blood through the thoracic duct. Once in the blood, the virus will have access to various parts of the body, including the liver, muscle, joints, and brain (Fig. 1) [3]. The pathological events associated with tissue infection are mostly subclinical in the liver (hepatocyte apoptosis) and lymphoid organs (adenopathy), whereas mononuclear cell infiltration and viral replication in the muscles and joints are associated with very strong pain, with some of the patients presenting arthritis [78].

\section{Immunopathogenesis}

The innate immune response is the first barrier against viruses, being able to inhibit viral replication through cytolytic and non-cytolytic mechanisms. IFN system plays an important role in limiting virus spread at an early stage of infection. In fact, in vitro growth of all alpha viruses can be greatly suppressed by the antiviral effects of IFN- $\alpha / \beta$ when it is added to cells prior to infection $[53,64,79]$. The finding that aberrant type I interferon signaling in mice leads to severe forms of CHIKF [53] further highlighted the important roles that cytokines play in the pathology of CHIKV infection. The pathogenesis of CHIKV infection is not well understood and is an area of intense investigation, with small animal and nonhuman primate models of acute and chronic disease recently being developed [24]. Disease signs and symptoms following infection with CHIKV have been associated with CHIKV infection of cells in musculoskeletal tissues, such as fibroblasts and osteoblasts, and infiltration of inflammatory cells — consisting predominantly of monocytes, macrophages, natural killer cells, and $\mathrm{T}$ cells - in musculoskeletal tissues. Recent works have demonstrated that mice lacking mature $\mathrm{T}$ and $\mathrm{B}$ cells and mice lacking $\mathrm{CD}^{+} \mathrm{T}$ cells had reduced joint swelling and less severe musculoskeletal tissue injury during the acute stage of CHIKV disease, suggesting a pathogenic role for $\mathrm{CD}^{+} \mathrm{T}$ cells in CHIKV disease [80, 81].

CHIKV interactions with monocytes and with other blood leukocytes induced a robust and rapid innate immune response with the production of specific chemokines and cytokines, including IFN- $\alpha$ [82]. Production of interleukin (IL), IL-4, IL-10, and IFN- $\gamma$ suggested the engagement of the adaptive immunity. This was confirmed by flow cytometry of circulating $\mathrm{T}$ lymphocytes that showed a CD8+ T lymphocyte response in the early stages of the disease and a CD4+ $\mathrm{T}$ lymphocyte mediated response in the later stages [82]. High levels of IL-6, IL-1 $\beta$, RANTES, monocyte chemoattractant protein 1 (MCP-1), monokine induced by IFN $-\gamma$ (MIG), and IP-10 were linked to CHIKV disease severity [24].

Cytokines may also contribute to chronic CHIKV disease, as persistent arthralgia has been associated with elevated levels of IL-6 and granulocyte-macrophage colony-stimulating factor (GM-CSF) [83]. Several studies have tried to identify the factors associated with chronic Chikungunya disease in groups of patients in Singapore [83], La Réunion [84], Dakshina Kannada (India) [85, 86], and Emilia Romagna (Italy) [87]. Regulatory mechanisms silencing the vigorous (even localized) inflammatory response seem to be required to prevent the establishment of chronic disease weeks or even months after viral clearance from the blood. The absence of such mechanisms leads to chronic arthralgia. In fact, in patients from the La Réunion study, various markers of inflammation (IFN- $\alpha$, IL-6, MCP-1/CCL-2, IL-8, and MMP2) have been detected in the synovial fluid of a patient suffering from chronic pain, but not in patients who fully recovered [84]. CHIKV has been shown to persist in various tissues for up to 44 days post-infection in monkeys, with CHIKV antigen and RNA detected in macrophages for 90 days and 55 days after infection, respectively [88]. Moreover, high plasma concentrations of IL-12 and IFN- $\alpha$ mRNA have reported in blood mononuclear cells after the convalescent phase, in patients with chronic disease, between 6 months and 1 year after infection [78, 84].

According to these findings, Chaaithanya and colleagues (2011) and Kelvin and colleagues (2011) reported high levels of Th1-type cytokines in the blood of patients with chronic 
disease $[86,87]$. Thus, despite certain discrepancies, the available studies suggest that chronic disease is associated with a de-regulation of inflammation during the acute and convalescence phases. This lack of regulation results in a deleterious inflammatory process that persists for $\geq 1$ year after the first clinical signs [78].

Concerning the possible implication of viral factors in the pathogenesis, the attention has been focused on the A226V mutation that has been associated with enhanced replication and fitness of CHIKV in A. albopictus vector and has also been shown to modulate cholesterol requirement for infection of insect cells [27]. The possible involvement of A226V mutation in enhancing human pathogenesis was investigated from Bordi and colleagues by testing the replication competence in primate cell cultures of two CHIKV isolates differing for the presence or absence of this mutation. The study revealed that the presence of A226V mutation did not influence the replication kinetics on primate cells. Moreover, the two isolates displayed very similar time course of cytopathic effect (CPE) appearance, number and extent of CHIKV antigenpositive cells, as well as shape of the virus-positive multicellular foci, thus suggesting a similar mechanism of spread of the virus in the infected cell cultures [89].

\section{Conclusions}

In the last decade, CHIKV has emerged as a major threat to global public health, spreading from the coast of Kenya throughout the Indian Ocean, Pacific, and Caribbean regions, and causing millions of cases of disease in over 50 countries. The recent notification of 4 cases of Chikungunya locally acquired infection in France has refreshed concerns about the possibility of renewed autochthonous transmission in Mediterranean countries.

CHIKV disease can be highly debilitating, and large epidemics have severe economic consequences. Thus, there is an urgent need for continued research into the epidemiology, pathogenesis, prevention, and treatment of these infections. At the moment, understanding CHIKV immunobiology is still in its infancy, and there is a long way to go before answers related to the interaction between virus and host immunity will be obtained. These will certainly be important in designing novel antiviral control strategies against the spread of CHIKV infection.

\section{Compliance with Ethics Guidelines}

Conflict of Interest All authors declare that they have no conflict of interest.

Human and Animal Rights and Informed Consent This article does not contain any studies with human or animal subjects performed by any of the authors.

\section{References}

Papers of particular interest, published recently, have been highlighted as:

- Of importance

1. Taubitz W, Cramer JP, Kapaun A, Pfeffer M, Drosten C, Dobler G, et al. Chikungunya fever in travelers: clinical presentation and course. Clin Infect Dis. 2007;1(45):e1-4.

2. European Centre for Disease Prevention and Control. Rapid Risk Assessment. Chikungunya outbreak in Caribbean region 25 June 2014. http://ecdc.europa.eu/en/publications/Publications/ chikungunya-caribbean-june-2014-risk-assessment.pdf

3. Caglioti C, Lalle E, Castilletti C, Carletti F, Capobianchi MR, Bordi L. Chikungunya virus infection: an overview. New Microbiol. 2013;36(3):211-27.

4. Burt FJ, Rolph MS, Rulli NE, Mahalingam S, Heise MT. Chikungunya: a re-emerging virus. Lancet. 2012;379(9816):66271.

5. Pialoux G, Gaüzère BA, Jauréguiberry $\mathrm{S}$, Strobel M. Chikungunya, an epidemic arbovirosis. Lancet Infect Dis. 2007;7(5):319-27.

6. Jain M, Rai S, Chakravarti A. Chikungunya: a review. Trop Doc. 2008;38(2):70-2.

7. Enserink M. Infectious diseases. Massive outbreak draws fresh attention to little-known virus. Science. 2006;311(5764):1085.

8. Mavalankar D, Shastri P, Raman P. Chikungunya epidemic in India: a major public-health disaster. Lancet Infect Dis. 2007;7(5):306-7.

9. Fusco FM, Puro V, Di Caro A, Nicastri E, Carannante N, Faella FS, et al. Cases of Chikungunya fever in Italy in travellers returning from the Indian Ocean and risk of introduction of the disease to Italy. Infez Med. 2006;14(4):238-45.

10. Rezza G, Nicoletti L, Angelini R, Romi R, Finarelli AC, Panning $\mathrm{M}$, et al. Infection with Chikungunya virus in Italy: an outbreak in a temperate region. Lancet. 2007;370(9602):1840-6.

11. Charrel R, de Lamballerie X. Chikungunya in north-eastern Italy: a consequence of seasonal synchronicity. Euro Surveill. 2008;13(1).

12. Grandadam $M$, Caro V, Plumet $S$, Thiberge JM, Souarès Y, Failloux $\mathrm{AB}$, et al. Chikungunya virus, southeastern France. Emerg Infect Dis. 2011;17(5):910-3.

13. Dupont-Rouzeyrol M, Caro V, Guillaumot L, Vazeille M, D'Ortenzio E, Thiberge JM, et al. Chikungunya virus and the mosquito vector Aedes aegypti in New Caledonia (South Pacific Region). Vector Borne Zoonotic Dis. 2012;12(12):1036-41. In this paper is described the introduction of a fourth lineage of CHIKV.

14. Horwood PF, Reimer LJ, Dagina R, Susapu M, Bande G, Katusele $\mathrm{M}$, et al. Outbreak of chikungunya virus infection, Vanimo. Papua New Guinea Emerg Infect Dis. 2013;19(9):1535-8.

15. Zayed A, Awash AA, Esmail MA, Al-Mohamadi HA, Al-Salwai M, Al-Jasari A, et al. Detection of Chikungunya virus in Aedes aegypti during 2011 outbreak in Al Hodayda. Yemen Acta Trop. 2012;123(1):62-6.

16. Wangchuk S, Chinnawirotpisan P, Dorji T, Tobgay T, Dorji T, Yoon IK, et al. Chikungunya fever outbreak, Bhutan, 2012. Emerg Infect Dis. 2013;19(10):1681-4.

17. Morrison TE. Reemergence of Chikungunya virus. J Virol. 2014;88(20):11644-7.

18. Morens DM, Fauci AS. Chikungunya at the door-déjà vu all over again? N Engl J Med. 2014;371(10):885-7.

19. ProMED-mail. Chikungunya: Caribbean. ProMED-mail 25 Jun 2014: 20140625.2563740. <http://www.promedmail.org>.

20. World Health Organization (WHO). Global Alert and Response (GAR). Chikungunya - France Disease outbreak news 23 
October 2014. http://www.who.int/csr/don/23-october-2014chikungunya/en/

21. Peyrefitte CN, Rousset D, Pastorino BA, Pouillot R, Bessaud M, Tock F, et al. Chikungunya virus, Cameroon, 2006. Emerg Infect Dis. 2007;13(5):768-71.

22. Peyrefitte CN, Bessaud M, Pastorino BA, Gravier P, Plumet S, Merle OL, et al. Circulation of Chikungunya virus in Gabon, 2006-2007. J Med Virol. 2008;80(3):430-3.

23. Weaver SC, Osorio JE, Livengood JA, Chen R, Stinchcomb DT. Chikungunya virus and prospects for a vaccine. Expert Rev Vaccines. 2012;11(9):1087-101.

24. Plante K, Wang E, Partidos CD, Weger J, Gorchakov R, Tsetsarkin $\mathrm{K}$, et al. Novel Chikungunya vaccine candidate with an IRES-based attenuation and host range alteration mechanism. PLoS Pathog. 2011;7:e1002142.

25. Charrel RN, de Lamballerie X, Raoult D. Chikungunya outbreaks - the globalization of vector-borne diseases. N Engl J Med. 2007;356(8):769-71.

26. Vega-Rúa A, Zouache K, Girod R, Failloux AB, Lourenço-deOliveira R. High level of vector competence of Aedes aegypti and Aedes albopictus from ten American countries as a crucial factor in the spread of Chikungunya virus. J Virol. 2014;88(11):6294-306.

27. Tsetsarkin KA, Vanlandingham DL, McGee CE, Higgs S. A single mutation in Chikungunya virus affects vector specificity and epidemic potential. PLoS Pathog. 2007;3(12):e201.

28. Vazeille M, Moutailler S, Coudrier D, Rousseaux C, Khun H, Huerre M, et al. Two Chikungunya isolates from the outbreak of La Réunion (Indian ocean) exhibit different patterns of infection in the mosquito, Aedes albopictus. PLoS One. 2007;2(11):e1168.

29. Volk SM, Chen R, Tsetsarkin KA, Adams AP, Garcia TI, Sall AA, et al. Genome-scale phylogenetic analyses of Chikungunya virus reveal independent emergences of recent epidemics and various evolutionary rates. J Virol. 2010;84(13):6497-504

30. Arias-Goeta C, Moutailler S, Mousson L, Zouache K, Thiberge JM, Caro V, et al. Chikungunya virus adaptation to a mosquito vector correlates with only few point mutations in the viral envelope glycoprotein. Infect Genet Evol. 2014;24:116-26.

31. Arankalle VA, Shrivastava S, Cherian S, Gunjikar RS, Walimbe AM, Jadhav SM, et al. Genetic divergence of Chikungunya viruses in India (1963-2006) with special reference to the 2005-2006 explosive epidemic. J Gen Virol. 2007;88(Pt 7):1967-76.

32. Tsetsarkin KA, McGee CE, Volk SM, Vanlandingham DL, Weaver SC, Higgs S. Epistatic roles of E2 glycoprotein mutations in adaption of Chikungunya virus to Aedes albopictus and Ae. aegypti mosquitoes. PLoS One. 2009;4(8):e6835.

33. Tsetsarkin KA, Chen R, Leal G, Forrester N, Higgs S, Huang J, et al. Chikungunya virus emergence is constrained in Asia by lineage-specific adaptive landscapes. Proc Natl Acad Sci U S A. 2011;108(19):7872-7.

34. Tsetsarkin KA, Chen R, Yun R, Rossi SL, Plante KS, Guerbois M, et al. Multi-peaked adaptive landscape for Chikungunya virus evolution predicts continued fitness optimization in Aedes albopictus mosquitoes. Nat Commun. 2014;5:4084.

35. Wolfe ND, Kilbourn AM, Karesh WB, Rahman HA, Bosi EJ, Cropp BC, et al. Sylvatic transmission of arboviruses among Bornean orangutans. Am J Trop Med Hyg. 2001;64(5-6):310-6.

36. Inoue S, Morita $\mathrm{K}$, Matias RR, Tuplano JV, Resuello RR, Candelario JR, et al. Distribution of three arbovirus antibodies among monkeys (Macaca fascicularis) in the Philippines. J Med Primatol. 2003;32(2):89-94.

37. Lam SK, Chua KB, Hooi PS, Rahimah MA, Kumari S, Tharmaratnam M, et al. Chikungunya infection-an emerging disease in Malaysia. Southeast Asian J Trop Med Public Health. 2001;32(3):447-51
38. Robinson MC. An epidemic of virus disease in Southern Province, Tanganyika Territory, in 1952-53 I. Clinical features. Tra'ns R Soc Trop Med Hyg. 1955;49(1):28-32.

39. Hochedez P, Jaureguiberry S, Debruyne M, Bossi P, Hausfater P, Brucker $\mathrm{G}$, et al. Chikungunya infection in travelers. Emerg Infect Dis. 2006;12(10):1565-7.

40. Quatresous I. Investigation Group. E-alert 27 January: Chikungunya outbreak in Reunion, a French overseas department. Euro Surveill. 2006;11(2), E060202.1.

41. Saxena SK, Singh M, Mishra N, Lakshmi V. Resurgence of Chikungunya virus in India: an emerging threat. Euro Surveill. 2006;11(8), E060810.2.

42. Fourie ED, Morrison JG. Rheumatoid arthritic syndrome after Chikungunya fever. S Afr Med J. 1979;56(4):130-2.

43. Brighton SW, Prozesky OW, de la Harpe AL. Chikungunya virus infection. A retrospective study of 107 cases. S Afr Med J. 1983;63(9):313-5.

44. Kennedy AC, Fleming J, Solomon L. Chikungunya viral arthropathy: a clinical description. J Rheol. 1980;7(2):231-6.

45. Mahendradas P, Ranganna SK, Shetty R, Balu R, Narayana KM, Babu RB, et al. Ocular manifestations associated with Chikungunya. Ophthalmology. 2008;115(2):287-91.

46. Mahalingam S, Meanger J, Foster PS, Lidbury BA. The viral manipulation of the host cellular and immune environments to enhance propagation and survival: a focus on RNA viruses. J Leukoc Biol. 2002;72(3):429-39.

47. Jacups SP, Whelan PI, Currie BJ. Ross River virus and Barmah Forest virus infections: a review of history, ecology, and predictive models, with implications for tropical northern Australia. Vector Borne Zoonotic Dis. 2008;8(2):283-97.

48. Chatterjee SN, Chakravarti SK, Mitra AC, Sarkar JK. Virological investigation of cases with neurological complications during the outbreak of haemorrhagic fever in Calcutta. J Indian Med Assoc. 1965;45(6):314-6.

49. Chatterjee SN, Sarkar JK. Electron microscopic studies of suckling mouse brain cells infected with Chikungunya virus. Indian J Exp Biol. 1965;3(4):227-34.

50. Ravi V. Re-emergence of Chikungunya virus in India. Indian J Med Microbiol. 2006;24(2):83-4.

51. Wielanek AC, Monredon JD, Amrani ME, Roger JC, Serveaux JP. Guillain-Barré syndrome complicating a Chikungunya virus infection. Neurology. 2007;69(22):2105-7.

52. Lebrun $\mathrm{G}$, Chadda $\mathrm{K}$, Reboux $\mathrm{AH}$, Martinet $\mathrm{O}$, Gaüzère BA. Guillain-Barré syndrome after Chikungunya infection. Emerg Infect Dis. 2009;15(3):495-6.

53. Couderc T, Chrétien F, Schilte C, Disson O, Brigitte M, GuivelBenhassine F, et al. A mouse model for Chikungunya: young age and inefficient type-I interferon signaling are risk factors for severe disease. PLoS Pathog. 2008;4(2):e29.

54. Lemant J, Boisson V, Winer A, Thibault L, André H, Tixier F, et al. Serious acute Chikungunya virus infection requiring intensive care during the Reunion Island outbreak in 2005-2006. Crit Care Med. 2008;36(9):2536-41.

55. Josseran L, Paquet C, Zehgnoun A, Caillere N, Le Tertre A, Solet JL, et al. Chikungunya disease outbreak. Emerg Infect Dis. 2006;12(12):1994-5.

56. Beesoon S, Funkhouser E, Kotea N, Spielman A, Robich RM. Chikungunya fever, Mauritius, 2006. Emerg Infect Dis. 2008;14(2):337-8.

57. Mavalankar D, Shastri P, Bandyopadhyay T, Parmar J, Ramani KV. Increased mortality rate associated with chikungunya epidemic, Ahmedabad, India. Emerg Infect Dis. 2008;14(3):412-5.

58. Fusco FM, Nicastri E, Nisii C, Di Caro A, Ippolito G. Chikungunya fever, a re-emerging disease. Tropical and Emerging Infectious Diseases. 2010; Maltezou HC and Gikas A, 93-110, ISBN: 97881-308-0389-0. 
59. Schwartz O, Albert ML. Biology and pathogenesis of Chikungunya virus. Nat Rev Microbiol. 2010;8(7):491-500.

60. Solignat M, Gay B, Higgs S, Briant L, Devaux C. Replication cycle of Chikungunya: a re-emerging arbovirus. Virology. 2009;393(2): 183-97.

61. Voss JE, Vaney MC, Duquerroy S, Vonrhein C, Girard-Blanc C, Crublet E, et al. Glycoprotein organization of Chikungunya virus particles revealed by X-ray crystallography. Nature. 2010;468(7324):709-12.

62. Wintachai P, Wikan N, Kuadkitkan A, Jaimipuk T, Ubol S, Pulmanausahakul R, et al. Identification of prohibitin as a Chikungunya virus receptor protein. J Med Virol. 2012;84(11): 1757-70.

63. Strauss JH, Strauss EG. The alphaviruses: gene expression, replication, and evolution. Microbiol Rev. 1994;58(3):491-562.

64. Sourisseau M, Schilte C, Casartelli N, Trouillet C, GuivelBenhassine F, Rudnicka D, et al. Characterization of reemerging Chikungunya virus. PLoS Pathog. 2007;3(6):e89.

65. Bernard E, Solignat M, Gay B, Chazal N, Higgs S, Devaux C, et al. Endocytosis of Chikungunya virus into mammalian cells: role of clathrin and early endosomal compartments. PLoS One. 2010;5(7): e11479.

66. Lee RC, Hapuarachchi HC, Chen KC, Hussain KM, Chen H, Low $\mathrm{SL}$, et al. Mosquito cellular factors and functions in mediating the infectious entry of Chikungunya virus. PLoS Negl Trop Dis. 2013;7(2):e2050.

67. Acosta EG, Castilla V, Damonte EB. Functional entry of dengue virus into Aedes albopictus mosquito cells is dependent on clathrinmediated endocytosis. J Gen Virol. 2008;89(Pt 2):474-84.

68. Suksanpaisan L, Susantad T, Smith DR. Characterization of dengue virus entry into HepG2 cells. J Biomed Sci. 2009;16:17.

69. Paingankar MS, Arankalle VA. Identification of Chikungunya virus interacting proteins in mammalian cells. J Biosci. 2014;39(3):38999. This paper shed light onto the important role of actin, actinassociated protein and HSP7O in establishing CHIKV infection in mammalian cells.

70. Lim PJ, Chu JJ. A polarized cell model for Chikungunya virus infection: entry and egress of virus occurs at the apical domain of polarized cells. PLoS Negl Trop Dis. 2014;8(2):e2661. This study demonstrated the polarized entry of CHIKV towards the apical domain of polarized cells.

71. Shirako Y, Strauss JH. Regulation of Sindbis virus RNA replication: uncleaved $\mathrm{P} 123$ and nsP4 function in minus-strand RNA synthesis, whereas cleaved products from P123 are required for efficient plus-strand RNA synthesis. J Virol. 1994;68(3):1874-85.

72. Thiberville SD, Moyen N, Dupuis-Maguiraga L, Nougairede A, Gould EA, Roques P, et al. Chikungunya fever: epidemiology, clinical syndrome, pathogenesis and therapy. Antiviral Res. 2013;99(3):345-70.

73. Das I, Basantray I, Mamidi P, Nayak TK, Chattopadhyay BMP, Chattopadhyay S, et al. Heat shock protein 90 positively regulates Chikungunya virus replication by stabilizing viral non-structural protein nsP2 during infection. PLoS One. 2014;9(6):e100531.

74. Singh SK, Unni SK. Chikungunya virus: host pathogen interaction. Rev Med Virol. 2011;21(2):78-88.

75. Perera R, Owen KE, Tellinghuisen TL, Gorbalenya AE, Kuhn RJ. Alphavirus nucleocapsid protein contains a putative coiled coil alpha-helix important for core assembly. J Virol. 2001;75(1):1-10.
76. Ekstrom M, Liljestrom $\mathrm{P}$, Garoff $\mathrm{H}$. Membrane protein lateral interactions control Semliki Forest virus budding. EMBO J. 1994;13(5): 1058-64.

77. Her Z, Malleret B, Chan M, Ong EK, Wong SC, Kwek DJ, et al. Active infection of human blood monocytes by Chikungunya virus triggers an innate immune response. J Immunol. 2010;184(10): 5903-13.

78. Dupuis-Maguiraga L, Noret M, Brun S, Le Grand R, Gras G, Roques P. Chikungunya disease: infection-associated markers from the acute to the chronic phase of arbovirus-induced arthralgia. PLoS Negl Trop Dis. 2012;6(3):e1446.

79. Schilte C, Couderc T, Chretien F, Sourisseau M, Gangneux N, Guivel-Benhassine F, et al. Type I IFN controls Chikungunya virus via its action on nonhematopoietic cells. J Exp Med. 2010;207(2): 429-42.

80. Teo TH, Lum FM, Claser C, Lulla V, Lulla A, Merits A, et al. A pathogenic role for $\mathrm{CD} 4+\mathrm{T}$ cells during Chikungunya virus infection in mice. J Immunol. 2013;190(1):259-69.

81. Hawman DW, Stoermer KA, Montgomery SA, Pal P, Oko L, Diamond MS, et al. Chronic joint disease caused by persistent Chikungunya virus infection is controlled by the adaptive immune response. J Virol. 2013;87(24):13878-88.

82. Wauquier N, Becquart P, Nkoghe D, Padilla C, Ndjoyi-Mbiguino A, Leroy EM. The acute phase of Chikungunya virus infection in humans is associated with strong innate immunity and T CD8 cell activation. J Infect Dis. 2011;204(1):115-23.

83. Chow A, Her Z, Ong EK, Chen JM, Dimatatac F, Kwek DJ, et al. Persistent arthralgia induced by Chikungunya virus infection is associated with interleukin-6 and granulocyte macrophage colony-stimulating factor. J Infect Dis. 2011;203(2): 149-57.

84. Hoarau JJ, Jaffar Bandjee MC, Krejbich Trotot P, Das T, et al. Persistent chronic inflammation and infection by Chikungunya arthritogenic alphavirus in spite of a robust host immune response. J Immunol. 2010;184(10):5914-27.

85. Manimunda SP, Vijayachari P, Uppoor R, Sugunan AP, Singh SS, Rai SK, et al. Clinical progression of Chikungunya fever during acute and chronic arthritic stages and the changes in joint morphology as revealed by imaging. Trans R Soc Trop Med Hyg. 2010;104(6):392-9.

86. Chaaitanya IK, Muruganandam N, Sundaram SG, Kawalekar O, Sugunan AP, Manimunda SP, et al. Role of proinflammatory cytokines and chemokines in chronic arthropathy in CHIKV infection. Viral Immunol. 2011;24(4):265-71.

87. Kelvin AA, Banner D, Silvi G, Moro ML, Spataro N, Gaibani P, et al. Inflammatory cytokine expression is associated with Chikungunya virus resolution and symptom severity. PLoS Negl Trop Dis. 2011;5(8):e1279.

88. Labadie K, Larcher T, Joubert C, Mannioui A, Delache B, Brochard $\mathrm{P}$, et al. Chikungunya disease in nonhuman primates involves longterm viral persistence in macrophages. J Clin Invest. 2010;120(3): 894-906.

89. Bordi L, Meschi S, Selleri M, Lalle E, Castilletti C, Carletti F, et al. Chikungunya virus isolates with/without A226V mutation show different sensitivity to IFN-a, but similar replication kinetics in non human primate cells. New Microbiol. 2011;34(1):87-91. 